\title{
Morinda citrifolia Leaf Extract Suppressed Metastasised Cancer Progression via EGFR and MAPK Pathways
}

\section{다)(우(ㅇ)}

\section{Authors}

Swee-Ling Lim¹, Noordin M. Mustapha², Yong-Meng Goh², Heshu S. Rahman' ${ }^{1}$, Suhaila Mohamed

Affiliations

1 UPM-MAKNA Cancer Research Laboratory, Institute of Bioscience, Universiti Putra Malaysia, Serdang, Selangor, Malaysia

2 Faculty of Veterinary Medicine, Universiti Putra Malaysia, Serdang, Selangor, Malaysia

Key words

Morinda citrifolia, Rubiaceae, scopoletin, epicatechin, carcinogenesis, angiogenesis

received 12.09 .2016

revised 20.03.2017

accepted 21.03.2017

Bibliography

DOI https://doi.org/10.1055/s-0043-107030

Planta Med Int Open 2017; 4: e8-e16

(c) Georg Thieme Verlag KG Stuttgart · New York

ISSN 2509-9264

Correspondence

Suhaila Mohamed

UPM-MAKNA Cancer-Research Laboratory

Institute of Bioscience

Universiti Putra Malaysia

43400 Serdang

Selangor

Malaysia

Tel.: +60/389/47 2186, Fax: +60/389/47 2101

mohamed.suhaila@gmail.com
Supporting information HPLC and LC-MS profiles of the extract standardised to scopoletin and epicatechin and a listing of bioactive chemical contents of M. citrifolia leaf are available online at http://www.thieme-connect.de/products.

\begin{abstract}
Morinda citrifolia leaf has anti-inflammatory and immune enhancing effects against lung cancer. The effects of the extract on metastasised lung and liver cancer tissues were compared to Erlotinib (an anticancer drug) for cancer aggression, proliferation, and angiogenesis. Forty $\mathrm{Balb} / \mathrm{c}$ mice were induced to develop metastatic lung and liver tumours via xenograft subcutaneous injection of non-small cell lung cancer A549 cells $\left(2 \times 10^{7}\right.$ cells/mouse) into their backs. The extract ( 150 and $300 \mathrm{mg} /$ $\mathrm{kg}$ body weight) and Erlotinib (50 mg/kg body weight) were fed to the mice for 21 days, and the microstructure and mRNA expressions of the tumour tissues were analysed. The extract dose-dependently downregulated RAC-alpha serine/threonine-protein kinase, B cell leukaemia/ lymphoma 2, mitogen-activated protein kinase kinase kinase 14, mitogen-activated protein kinase 1 , and vascular endothelial growth factor alpha in these tissues. The scopoletin (coumarin) and epicatechin (flavonoid) standardised extract also mitigated the cancerous tissues microstructure changes, and suppressed the tissue remodeling enzyme (matrix metallopeptidase 9) and angiogenesis biomarkers (epidermal growth factor receptor and integrin). The $300 \mathrm{mg}$ extract $/ \mathrm{kg}$ body weight was more effective than the $50 \mathrm{mg}$ Erlotinib/kg body weight in suppressing the lung and liver tumoor metastasis. The extract inhibited the cancer aggression by interfering with epidermal growth factor receptor and mitogen-activated protein kinase carcinogenesis pathways, and suppressing proliferation, tissue remodelling, and angiogenesis without any observable side effects at the given dose.
\end{abstract}

\section{Abbreviations}

IL MAP3K14 mitogen-activated protein kinase kinase kinase 14 MAPK MMP9 NFKB
RAC-alpha serine/threonine-protein kinase B cell leukaemia/lymphoma 2 chemokine (C-X-C motif) ligand extracellular matrix epidermal growth factor receptor haematoxylin and eosin immunohistochemistry interleukin mitogen-activated protein kinase matrix metallopeptidase 9 nuclear factor kappa-light-chain-enhancer of activated B
NOAEL no observed-adverse-effect level

NSCLC non-small cell lung cancer

PI3K phosphatidylinositol 3-kinase

RAF RAF proto-oncogene serine/threonine-protein kinase

VEGF vascular endothelial growth factor

VEGFA vascular endothelial growth factor alpha

\section{Introduction}

Cancer progression relies upon malignant cell proliferation and the generation of new blood vessels (angiogenesis) to sustain survival and invasion (metastasis). Lung and liver cancers are amongst the leading causes of cancer-related deaths worldwide (about 2 million new cases annually). Erlotinib is an FDA approved EGFR tyros- 
ine-kinase inhibitor for treating locally advanced or metastatic NSCLC [1]. In a phase III study, Erlotinib significantly improved the overall survival, relative to the supportive care for refractory stage IIIB/IV NSCLC [2,3]. However, Erlotinib often causes side effects such as weakness, diarrhoea, rash, shortness of breath, cough, fever and loss of appetite, dry eyes, unusual eyelash growth, swollen cornea, extreme tiredness, and nausea. Sometimes it causes more serious side effects such as interstitial lung disease, liver and kidney damage, gastrointestinal perforation, blistering and skin peeling, and bleeding and clotting problems, which may lead to a heart attack, stroke, and death [4].

The leaves of Morinda citrifolia L. (Rubiaceae) or noni (America)/ mengkudu (Malaysia) are often used as vegetables or salads. The M. citrifolia leaves contain epicatechin and scopoletin, purported to have immune-modulating [5], antioxidant, liver protective and wound healing effects without any acute, subacute, and subchronic oral toxicity [6]. The NOAEL of oral M. citrifolia leaves ethanolic extract is $1000 \mathrm{mg} / \mathrm{kg}$ [7]. M. citrifolia is beneficial for wound infections, pain, arthritis, swellings, and homeostasis. Morinda fruit has been reported to have immunostimulant, antioxidant, anticancer, and anti-inflammatory properties [8-10].

Patients and caregivers often use diets as complementary therapy to the prescribed anticancer drugs. This report investigated the mechanisms (antiproliferation, anti-metastasis and possibly antiangiogenesis) by which $\mathrm{M}$. citrifolia leaf extract (standardised to scopoletin and epicatechin) could prevent the spread of cancer in lung and liver metastasised tumours in vivo.

\section{Results and Discussion}

The control cancer-induced mice ( $\vee$ Fig. 1a) displayed two adenomatous growths in the pulmonary parenchyma of the lungs with large and medium-sized pseudostratified tumour cell clusters (black arrow) together with goblet-like granules within their cytoplasm (yellow arrow). They also showed two irregular tumour invasive glandular structures consisting of pseudostratified lepidic growth (cells) with a pink amorphous proteinaceous secretion within the glandular lumen ( $\vee$ Fig. 1b, black arrow). The light arrow shows free red blood cells within the alveolar lumen and pulmonary parenchyma. The cancer-induced mice treated with $300 \mathrm{mg}$ extract/kg body weight had smaller tumours, with almost similar lung morphology to the control normal mice, and indicated a $41 \%$ better antimetastatic effect than the $50 \mathrm{mg}$ Erlotinib/kg body weight treatment.

The metastasised liver tumours of the control cancer-induced mice ( $\triangleright$ Fig. 1c) showed $60 \%$ tumour infiltration (metastasis), which is indicated by poorly differentiated tumour cells and some areas of necrosis. After 3 weeks, the metastasised tumours in the control cancer-induced mice were $\sim 290 \mathrm{~mm}^{3}$, while tumours in the mice treated with 150 and $300 \mathrm{mg}$ extract $/ \mathrm{kg}$ body weight and $50 \mathrm{mg}$ Erlotinib/kg body weight were significantly smaller (50, 95, and $87 \%$ smaller, respectively). The mice treated with $150 \mathrm{mg}$ extract $/ \mathrm{kg}$ body weight showed tumour cell infiltration to the liver and metastatic foci formation, while the Erlotinib-treated mice showed hyperchromatic nuclei and hepatocytes cytoplasmic vacuolisation. The mice treated with $300 \mathrm{mg}$ extract $/ \mathrm{kg}$ body weight showed no such changes.
- Fig. 2 shows the control cancer-induced mice overexpressed the EGFR in the metastasised tumours (for both lung and liver). The mice treated with $300 \mathrm{mg}$ extract/ $\mathrm{kg}$ body weight suppressed the EGFR expression more effectively than those treated with $50 \mathrm{mg}$ Erlotinib/kg body weight and $150 \mathrm{mg}$ extract $/ \mathrm{kg}$ body weight. The lung tumours expressed MMP9, while the liver tumours expressed integrin- $\beta 1$ ( Fig. 3). These expressions were less severe in the extract- and Erlotinib-treated groups. The mice treated with $300 \mathrm{mg}$ extract/kg body weight had downregulated expression of MMP9 and integrin- $\beta 1$ in the tumours to near normal healthy levels. Integrin- $\beta 1$ is the most copiously expressed integrin in NSCLC [11]. High MMP9 expression is an indicator for aggressive tumour growth in NSCLC [12].

The $300 \mathrm{mg}$ extract/kg body weight treatment effectively downregulated the BCL2, AKT1, VEGFA, and MAP3K14 expressions in the lung tumours by more than threefold ( $>$ Fig. 4a). The $50 \mathrm{mg} / \mathrm{kg} \mathrm{Er}$ lotinib treatment only significantly downregulated the BCL2, AKT1, and MAPK1 expressions (but not VEGFA or MAP3K14), while the $150 \mathrm{mg} / \mathrm{kg}$ extract treatment only downregulated BCL2 and MAP3K14 expressions (relative to the untreated control cancer group). In the liver, the $300 \mathrm{mg} / \mathrm{kg}$ extract treatment also significantly $(p<0.05)$ downregulated BCL2, AKT1, VEGFA, and MAPK1 ( $\triangleright$ Fig. 4b) more effectively than the $50 \mathrm{mg} / \mathrm{kg}$ Erlotinib treatment.

This vegetable extract showed no adverse changes in the mice behaviour, body, or food and water intake at the given dose, with a reported oral NOAEL of $1000 \mathrm{mg} / \mathrm{kg}$ [7], unlike most cancer chemotherapy. The $300 \mathrm{mg} / \mathrm{kg}$ extract dose is equivalent to consuming about $100-125 \mathrm{~g}$ of fresh leaves daily for a $50-\mathrm{kg}$ adult (FDA animal dose to human conversion guidelines).

Epicatechin and scopoletin are common compounds in edible leaves and may be a potential dietary therapy against carcinogenesis. Scopoletin or epicatechin when used alone produces weak cytotoxic activities towards various cancer cell lines. The $\mathrm{IC}_{50}$ of scopoletin for A549 lung cancer was above $100 \mu \mathrm{M}$ [13]. Scopoletin was reported to boost the apoptosis of human prostate tumour PC3 cells [14] and the human leukaemia cell line HL-60 [15], while (-)-epicatechin could inhibit growth and induced apoptosis in SW480 human colon cancer cells [16]. When combined, epicatechin and scopoletin may synergistically suppress cell proliferation. Scopoletin possesses antiangiogenic properties by inhibiting (a) endothelial cells growth and migration, (b) extracellular signal-regulated kinase (ERK) 1/2 activation, (c) tube formation, and (d) VEGF expression through NFKB [13]. Scopoletin, which is a coumarin, also helped activate protein kinase C (PKC) to induce normal T lymphocytes cell proliferation without mitogen stimulus [17].

( - )-Epicatechin enhanced curcumin apoptotic effects towards human lung cancer cells [18]. It also impaired angiogenesis, arrested metastasis through metalloproteinases inhibition, and helped reverse multidrug resistance [19]. Erlotinib's antiangiogenic properties were demonstrated by its ability to inhibit human umbilical vein endothelial cells (HUVECs) growth and xenograft vessel density [20]. Kaempferol in the leaf extract can also inhibit cancer [5].

The VEGF/VEGF-receptor pathway involving the PI3K/AKT and RAS/RAF/MAPK pathways is important for cancer cell proliferation, angiogenesis, migration, and invasion [21]. The VEGF and PI3K/ AKT/MTOR pathway is critical for the fibronectin-integrin effects on proliferation. The control cancer-induced mice overexpressed 


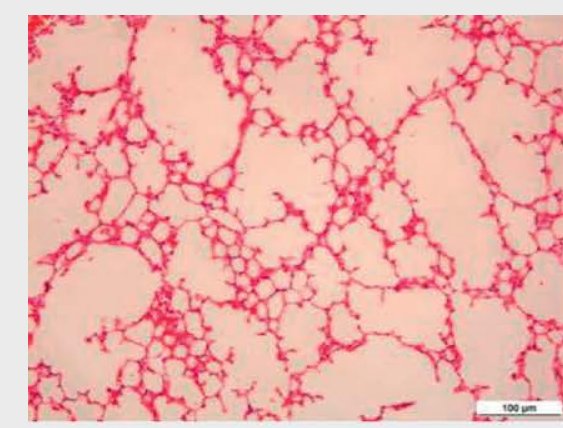

Control Normal

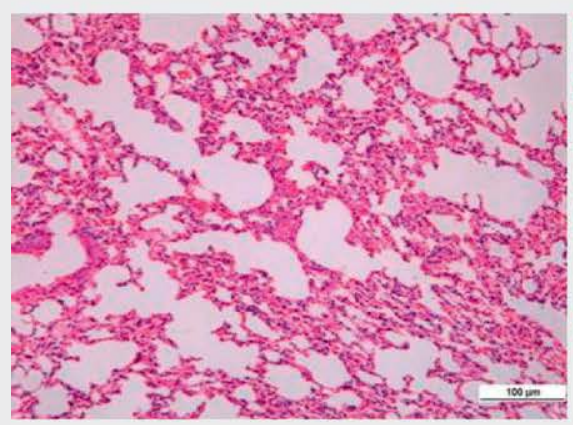

Erlotinib

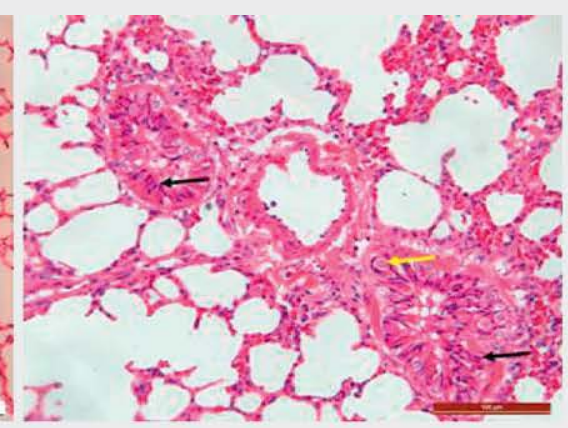

Untreated (A)

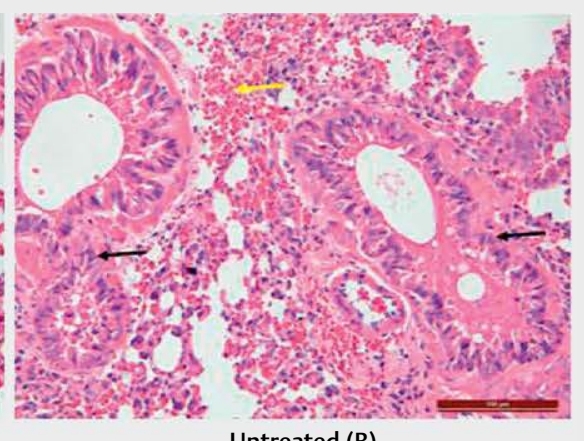

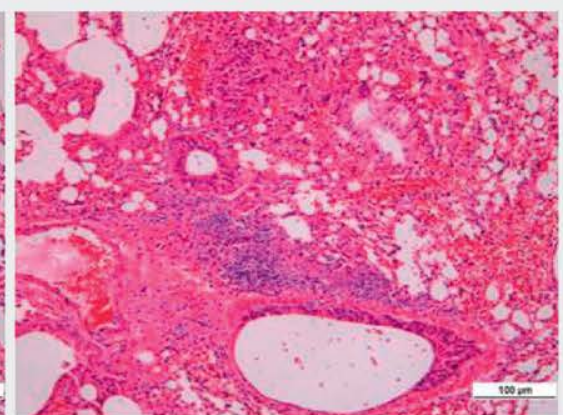

$150 \mathrm{mg} / \mathrm{kg}$ extract

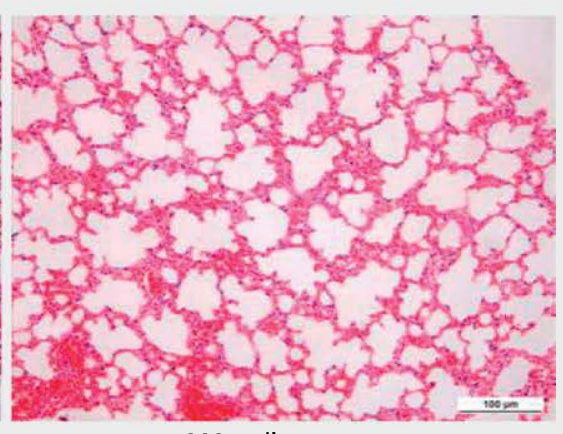

$300 \mathrm{mg} / \mathrm{kg}$ extract

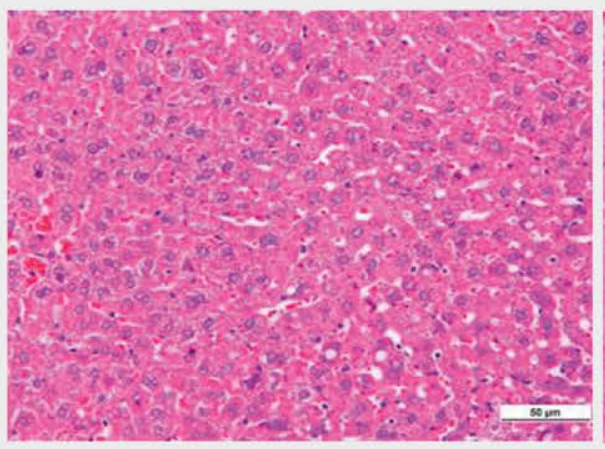

Control Normal

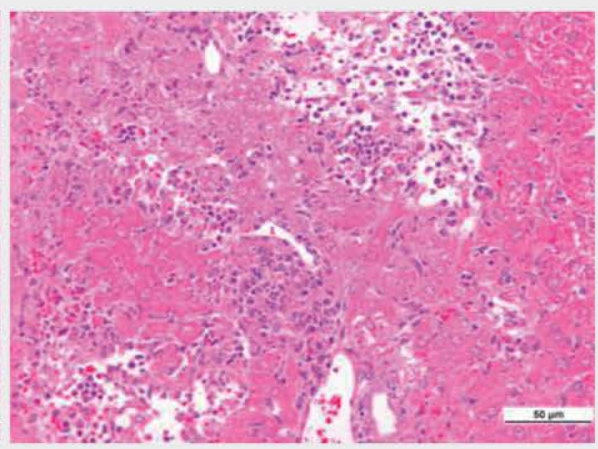

Untreated Cancer

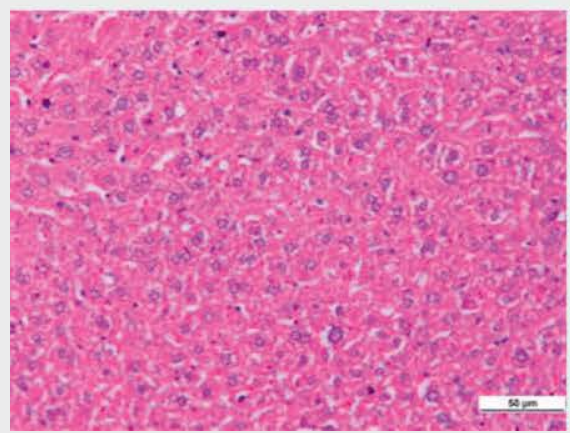

Erlotinib

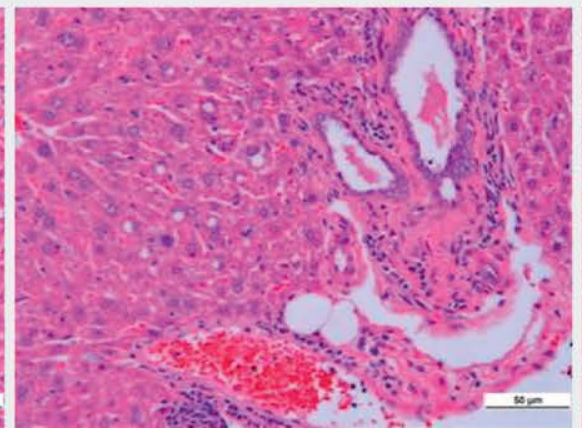

$150 \mathrm{mg} / \mathrm{kg}$ extract

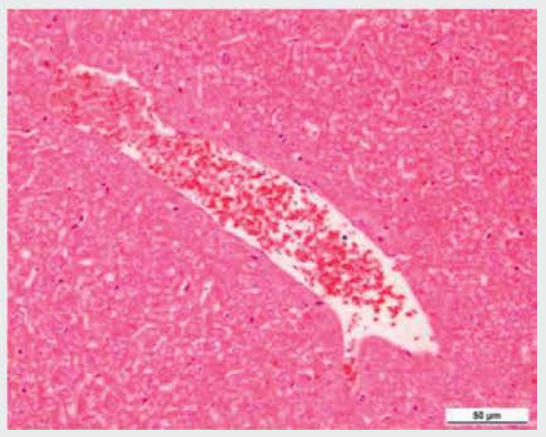

$300 \mathrm{mg} / \mathrm{kg}$ extract

- Fig. 1 The histological images of the metastasised cancers in the lungs and livers. [H\&E; x100; x200 (Untreated cancer a and b only)]. The adenomatous growth-like patterns in the lung were seen in the untreated control cancer group. The poorly differentiated metastasised tumour cells in the liver tumours were seen in the untreated control cancer group; (H\&E; x200).

EGFR in both lung and liver tumours (brown IHC staining and strong positive signal by DAB visualisation). The leaf extract dose-dependently restored the mice tumours towards normal healthy conditions by suppressing cancer cell proliferation and metastasis through the suppression of EGFR, MMP9, and integrin- $\beta 1$ activities, and by inhibiting the VEGF/EGFR/NFKB signalling pathway.

The VEGFA activates endothelial cells to produce MMPs that break down the stroma and ECM proteins [22] for angiogenesis and 

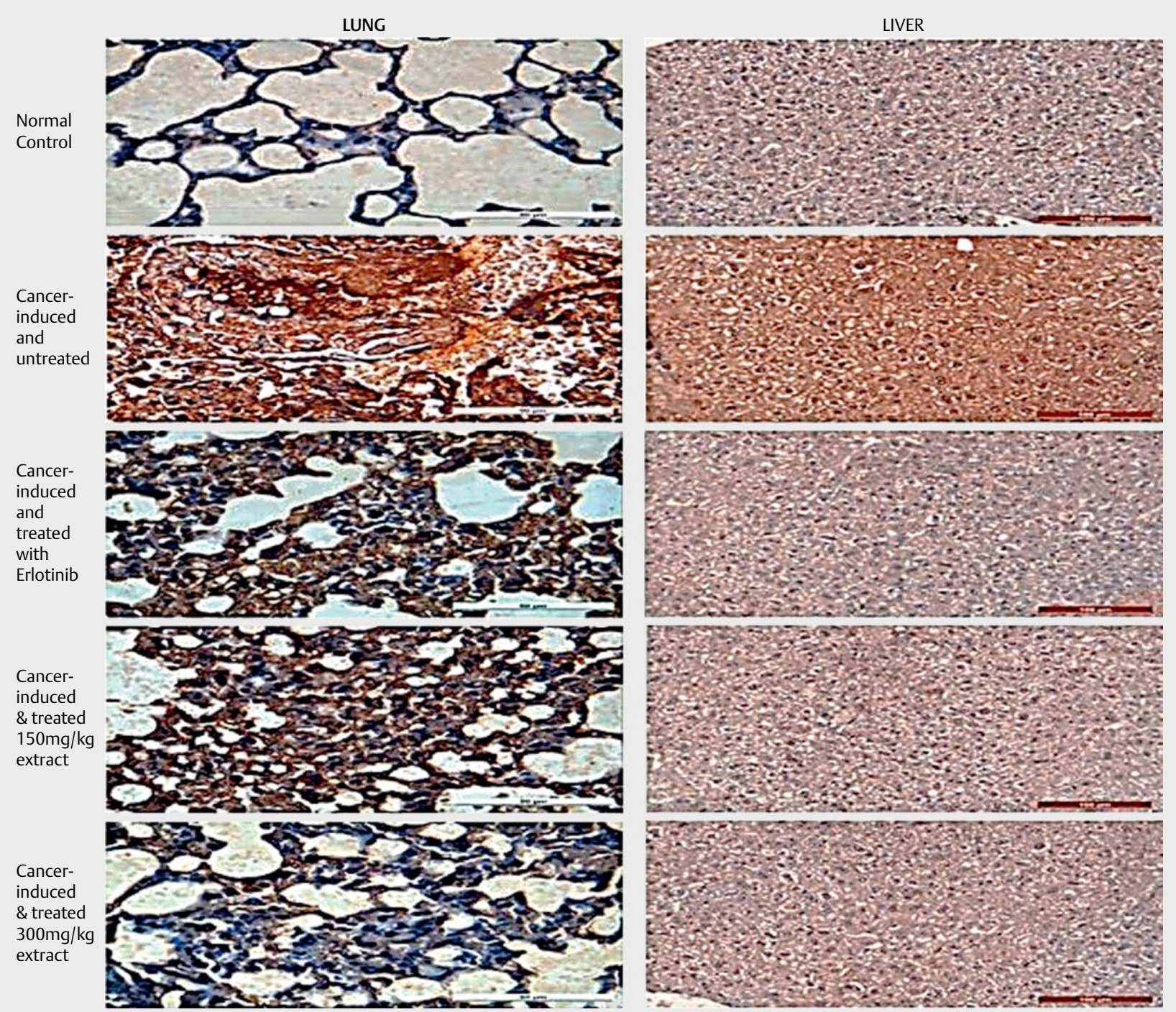

EGFR expressions in lungs
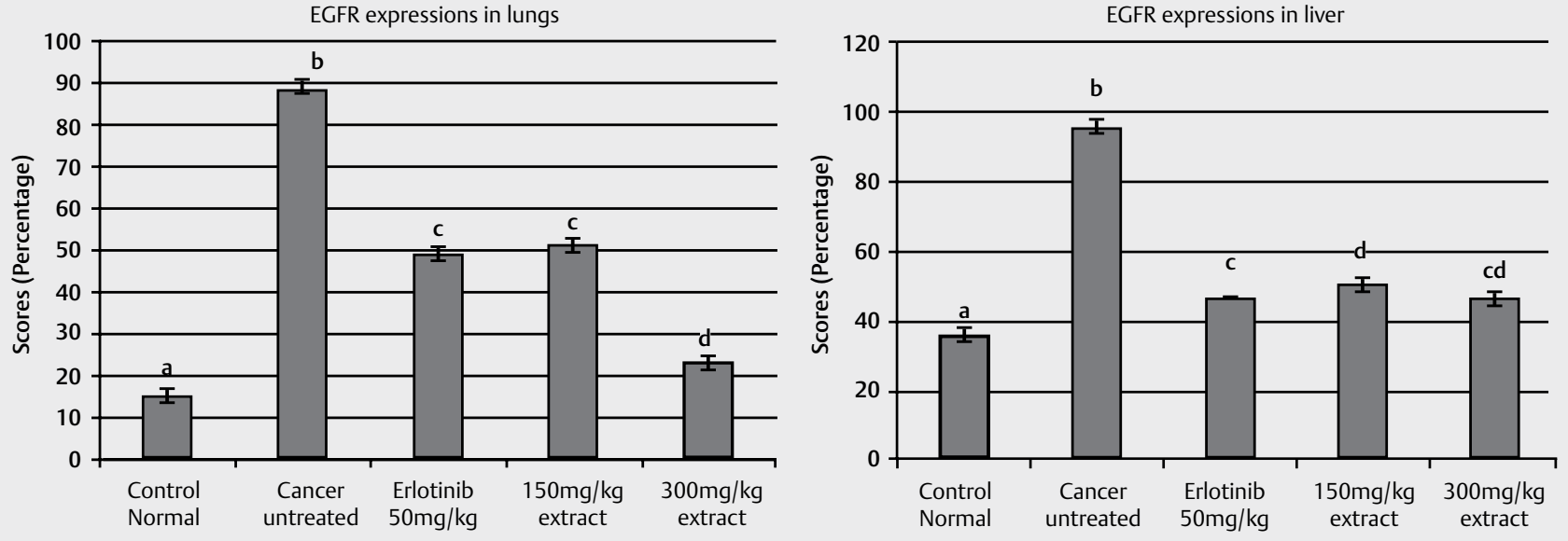

- Fig. 2 Immunohistochemical staining for EGFR in the metastasised tumours in the lungs and liver (lung IHC x200; liver IHC x100). Means with different superscript letters within the graph are significantly different $(p<0.05)$.

metastasis. The MMP9 are activated by fibronectin via the PI3K/ AKT or RAS/RHO/MAP pathway [23]. The vegetable extract dosedependently suppressed angiogenesis-related mRNA expressions (MMP9, VEGFA, and MAPK1), indicating reduced ECM degradation and remodelling. MMP9 is linked to the vascular remodelling and aggressive invasion of lung cancers [21]. The $300 \mathrm{mg}$ extract $/ \mathrm{kg}$ body weight treatment downregulated MAP3K14 (or NFKBinducing kinase; NIK) that consequently helped inhibit downstream 

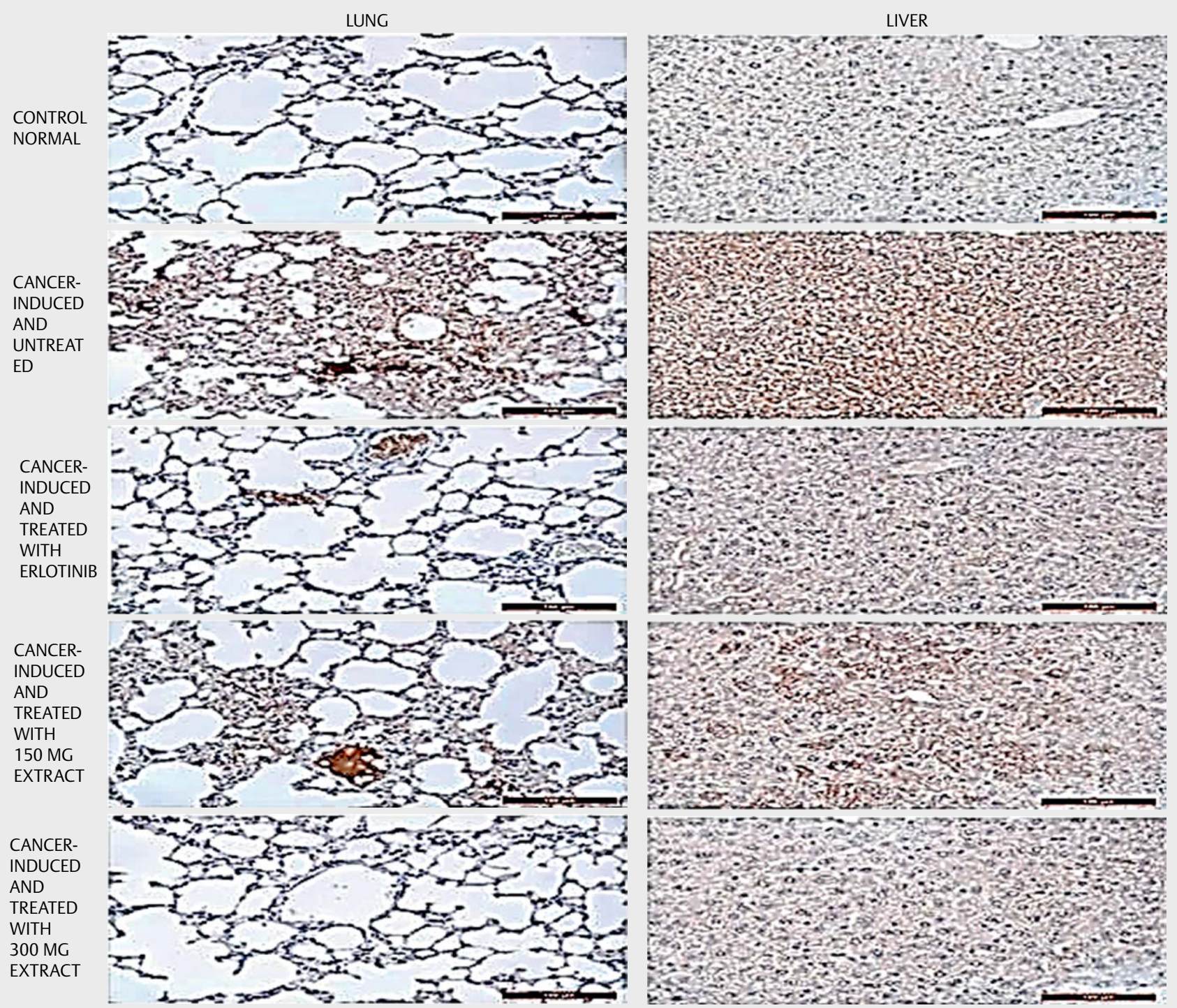

MMP9 EXPRESSION IN LUNGS

INTEGRIN B1 EXPRESSION IN LIVER
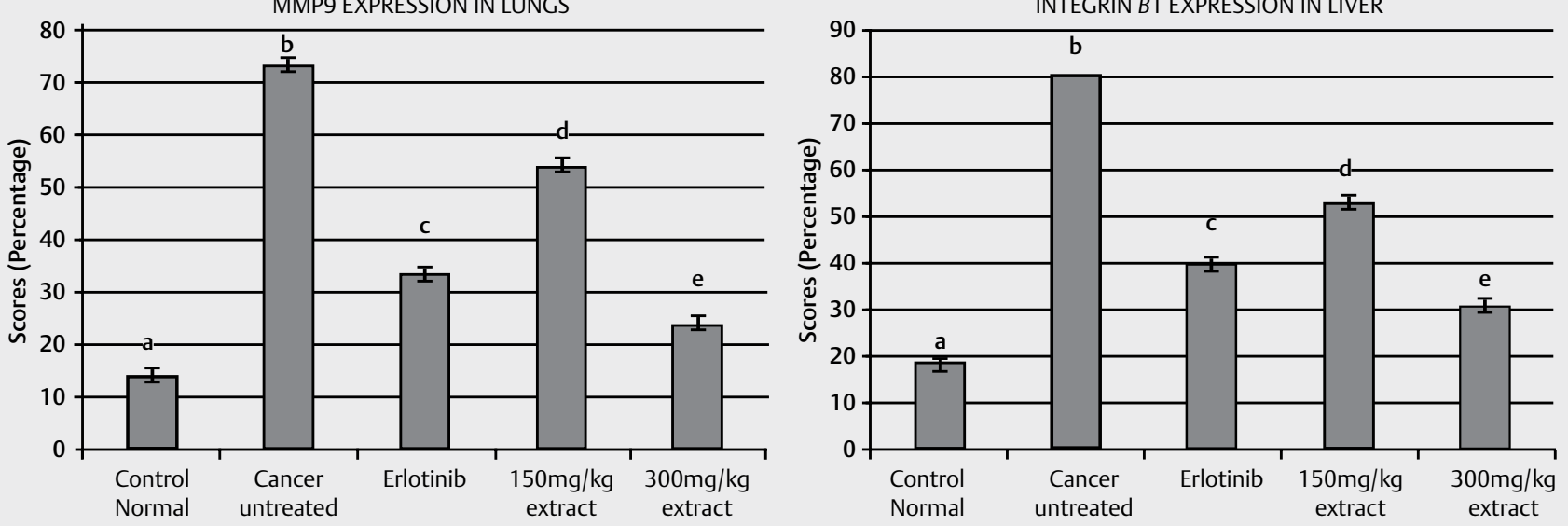

> Fig. 3 Immunohistochemical staining for MMP9 in the metastasised tumours in the lungs and integrin- $\beta 1$ staining in the livers ( $x 100)$. Means with different superscript letters within the graph are significantly different $(p<0.05)$. 
a

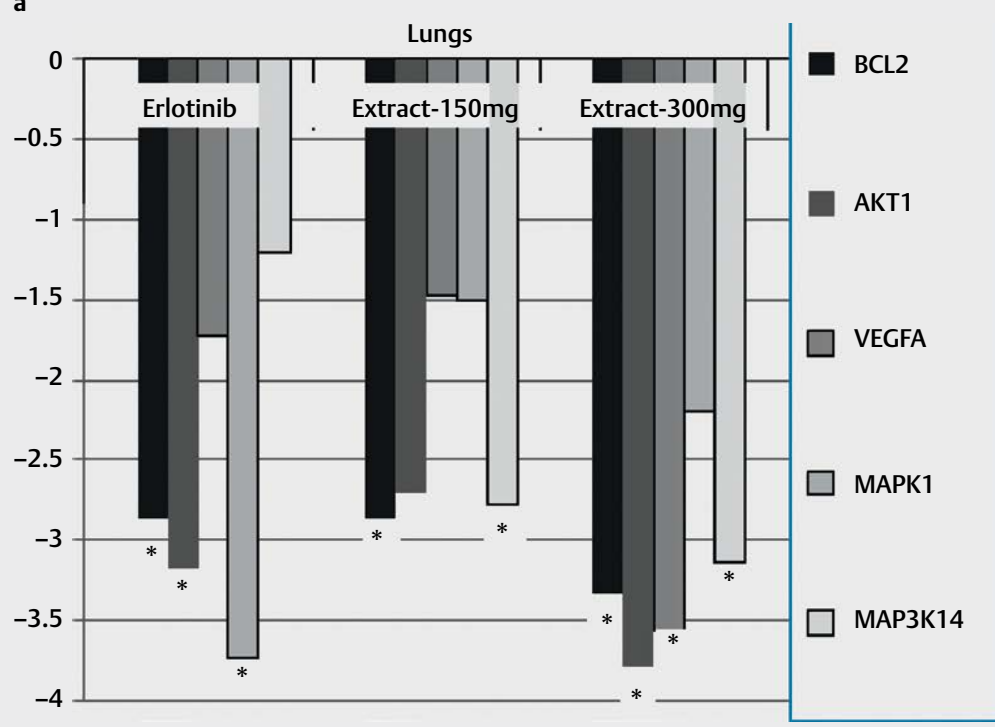

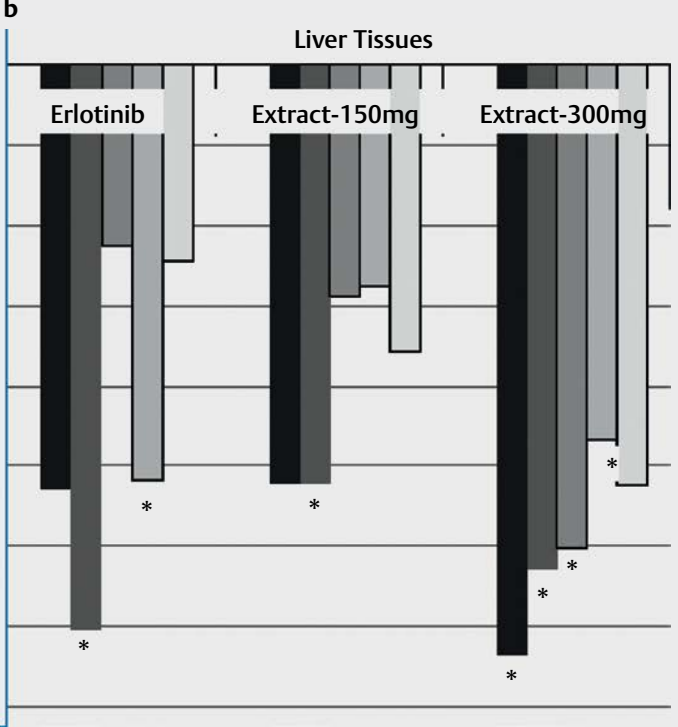

c

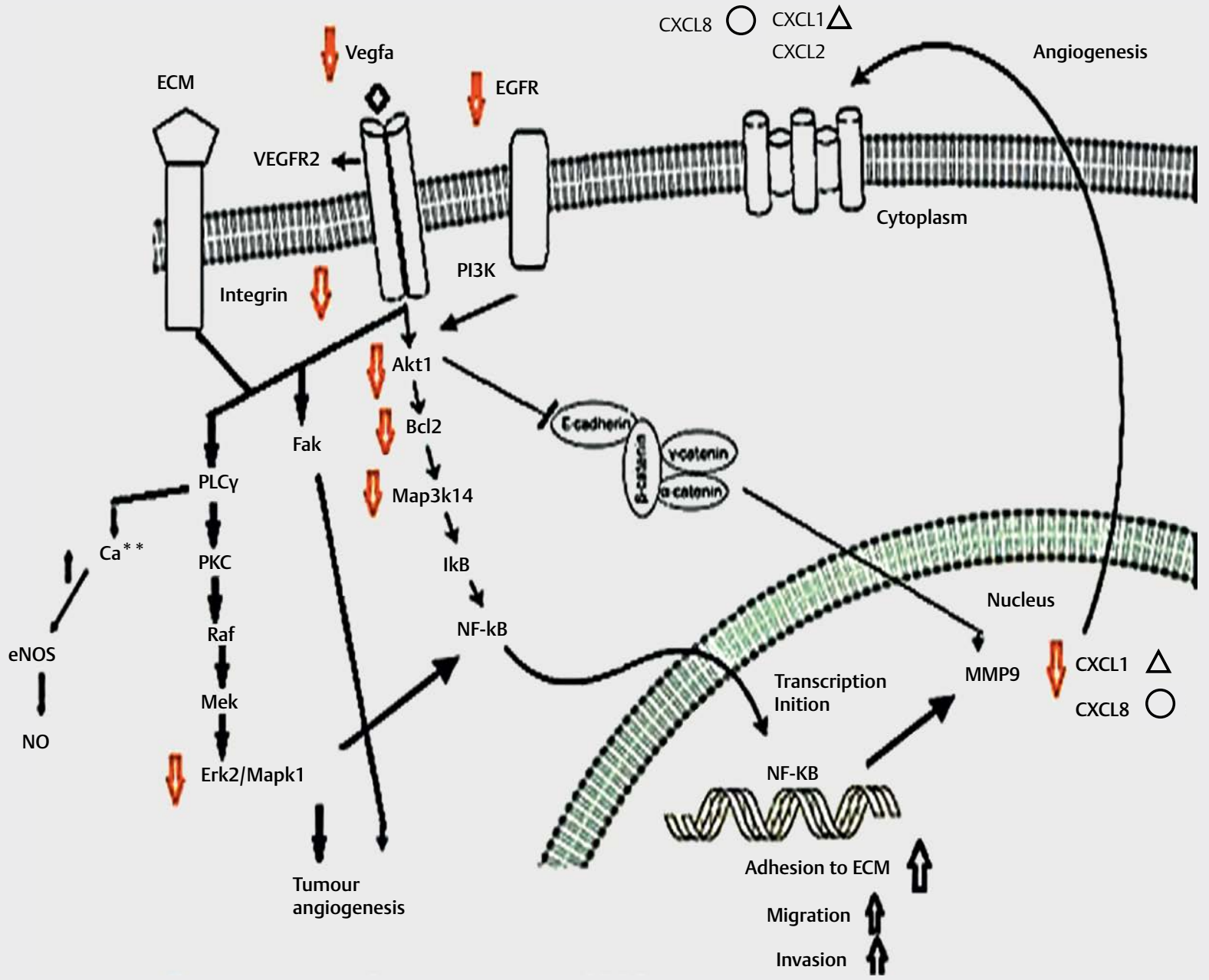

- Fig. 4 Mouse mRNA expressions in the lung $\mathbf{a}$, liver $\mathbf{b}$, and tumours $\mathbf{c}$, and schematic representation of the signalling pathways involved in the inhibition of angiogenesis and metastasis of lung adenocarcinoma by the Morinda leaf extract. * Significant difference $(p<0.05)$ between control and treatment groups. Adapted from https://www.qiagen.com/my/shop/genes-and-pathways/pathway-details/. 
metastasis genes including MMP9, VEGF, and the urokinase-type plasminogen activator receptor (UPAR) [24]. The $50 \mathrm{mg}$ Erlotinib/ $\mathrm{kg}$ body weight treatment did not show this effect.

The leaf extract also dose-dependently suppressed BCL2 and AKT1 expressions. The VEGF induces BCL2 expression. The upregulated BCL2 from the endothelial cells subsequently initiated the nuclear factor of kappa light polypeptide gene enhancer in the B cells inhibitor (IKB)/NFkB-dependent pathway, which elevated proangiogenic IL8 and CXCL1 expressions [25]. High AKT1 activation in all NSCLC subtypes induced endothelial cell migration via nitric oxide signalling [26]. AKT regulated tumour angiogenesis through downstream targets such as the mammalian target of rapamycin (mTOR)/ p7056K1 signalling axis, Forkhead box O (FOXO) inhibition, VEGF mRNA upregulation, nitric oxide synthase induction, and/or glycogen synthase kinase 3 beta (GSK3 $\beta$ ) inhibition [27].

The extract dose-dependently downregulated integrin- $\beta 1$ expression, which is necessary for angiogenesis and metastasis. Integrins are transmembrane signal transduction receptors for attachment from the ECM to the cells. The lung cancer cells are protected against apoptosis by the activation of integrin- $\beta 1$ via ECM proteins (including fibronectin) [20]. In NSCLC, overexpression of integrin $\alpha 5 \beta 1$ was negatively associated with patient survival [28]. Activation of integrin- $\beta 1$ on endothelial cells would trigger the transcription of a gene repertoire related to angiogenesis [heparin-binding epidermal growth factor-like growth factor (HB-EGF), IL8, CXCL1], adhesion [vascular cell adhesion molecule (VCAM), E-selectin], signal transduction (NFKB), and coagulation (tissue factor) [29]. Integrins modulate the angiogenesis-related cell signalling pathways of transmembrane protein kinases, such as receptor tyrosine kinases (RTK) [30].

The M. citrifolia (Noni) leaf extract was shown to inhibit proliferation and induced apoptosis in A549 cells $\left(\mathrm{IC}_{50}=23.47 \mu \mathrm{g} / \mathrm{mL}\right)$ and mouse Lewis (LL2) lung carcinoma cells $\left(\mathrm{IC}_{50}=5.50 \mu \mathrm{g} / \mathrm{mL}\right)$ in vitro by arresting the cancer cell cycle at G0/G1 phases and significantly increasing caspase-3/-8 without changing caspase- 9 levels [31]. The A549 is an NSCLC cell line, which is the most common lung adenocarcinoma subtype (with high mortality rate).

The vegetable previously demonstrated anticancer properties by increasing the proapoptotic (TRP53) genes, downregulating the pro-tumourigenesis genes (BIRC5, JAK2/STAT3/STAT5A), increasing anti-inflammatory biomarkers [IL4, IL10 and glucocorticoid receptor (NR3C1)], enhancing the antioxidant NFE2L2 [nuclear factor (erythroid-derived 2)-like 2]-dependent responses against oxidative injuries, modulating the immune responses (increasing blood lymphocytes, spleen tissues B cells, T cells, and natural killer cells), enhancing the tumour suppressor gene PTEN (phosphatase and tensin homolog), inhibiting cellular tumour growth genes (MDM2, RAF1, MTOR) [5], inducing G0/G1 cell cycle arrest and the extrinsic apoptosis pathway, reducing inflammatory markers cyclooxygenase 2 (COX2), increasing inflammatory cells clearance, enhancing the efflux of inflamed tissues, suppressing oedema accumulation, and inhibiting oxidative stress [31]. The vegetable extract was not cytotoxic on MRC5 normal lung cells ( $\left.I C_{50}>100.00 \mu \mathrm{g} / \mathrm{mL}\right)$.

These results demonstrated the Morinda leaf effects on metastasised cancer tissues microstructure, indicating the suppression of cancer cell proliferation and vascular and tissue remodelling, which were confirmed by mRNA expressions. The $300 \mathrm{mg}$ extract
/ kg body weight treatment appeared more effective than the $50 \mathrm{mg}$ Erlotinib / kg body weight treatment for most of the parameters measured.

\section{Materials and Methods}

Human lung adenocarcinoma (A549) cell lines were cultured in Kaighn's Modified Ham's F-12 (F-12K) medium (ATCC) [5] containing $10 \%$ fetal bovine serum (PAA) and $1 \%$ of $100 \mu \mathrm{g} / \mathrm{mL}$ penicillin and streptomycin (Biowest) in a humidified incubator at $37^{\circ} \mathrm{C}$ with $5 \%$ carbon dioxide.

\section{Extraction and chemical analysis}

The M. citrifolia leaves were identified and authenticated by the $\mathrm{Bi}$ odiversity Unit, Institute of Bioscience, UPM (Voucher No. SK2322/14). The leaves were dried and mixed in a ratio (w/v) of 1:5 with $50 \%$ ethanol in water. The total yield after extraction three times was $13.61 \%$. The extracts were analysed using HPLC (Waters 2996) with an Atlantis C 18 column $(4.6 \mathrm{~mm} \times 250 \mathrm{~mm}$; $5 \mu \mathrm{m}$, Waters Corp.) maintained at $25^{\circ} \mathrm{C}$. HPLC grade $\mathrm{MeOH}$, acetonitrile $(\mathrm{MeCN})$, and analytical grade trifluoroacetic acid (TFA) were obtained from Merck. The mobile phase consisted of three solvents: A: $\mathrm{MeCN}, \mathrm{B}$ : $\mathrm{MeOH}$, and C: $0.1 \%$ TFA in $\mathrm{H}_{2} \mathrm{O}(\mathrm{v} / \mathrm{v})$, programmed consecutively in linear gradients as follows: $0 \mathrm{~min}, 10 \% \mathrm{~A}, 10 \% \mathrm{~B}$, and $80 \% \mathrm{C} ; 15 \mathrm{~min}, 20 \% \mathrm{~A}, 20 \% \mathrm{~B}$, and $60 \% \mathrm{C} ; 26 \mathrm{~min}, 40 \% \mathrm{~A}, 40 \% \mathrm{~B}$, and $20 \% \mathrm{C} ; 28-39 \mathrm{~min}, 50 \% \mathrm{~A}, 50 \% \mathrm{~B}$, and $0 \% \mathrm{C}$; and $40-45 \mathrm{~min}$, $10 \% \mathrm{~A}, 10 \% \mathrm{~B}$, and $80 \% \mathrm{C}$. The elution was run at a flow rate of $1.0 \mathrm{~mL} \mathrm{~min}^{-1}$ with a $50-\mu \mathrm{L}$ sample injection volume and a UV spectra detector set at 210 and $450 \mathrm{~nm}$. Pure standards [scopoletin, and ( - )-epicatechin] were purchased from Sigma-Aldrich. The extract was standardised to scopoletin $(2.2 \%$, retention time, $\mathrm{Rt}=12.02 \mathrm{~min})$ and epicatechin $(3.4 \%, \mathrm{Rt}=9.17 \mathrm{~min})$ as the main compounds, which were qualitatively and quantitatively identified via the retention times and calibrated standard plots. Spiking with scopoletin and epicatechin produced sharp extended peaks at the specified retention times and their presence was further confirmed with LC-MS (Fig. 1S, Supporting Information). The epicatechin isomer in the extract was not determined because the HPLC retention times between isomers are usually either very close to each other or they may overlap, and LC-MS only confirmed the molecular weight of the parent and daughter molecules. There have not been many reports on the difference in biological activities between the epicatechin isomers. The isomer of the epicatechin may be determined in the future, since the scope of this work was on the animal studies and biological activities. Known chemical compounds in the M. citrifolia leaf have been reported and are shown in Table 1S, Supporting Information.

\section{Animal studies}

Male Balb/c mice (6 weeks old, weighing 19-20 g) from Faculty of Veterinary Medicine, University Putra Malaysia, were given standard chow and water, and kept in a 12-h light/12-h dark cycle [5]. The study was approved by the Institutional Animal Care and Use Committee (UPM/IACUC/AUP-R016/2013). The A549 cells $\left(2 \times 10^{7}\right.$ in $100 \mu \mathrm{LPBS}$ ) were injected subcutaneously into the mice backs [32]. When the metastasised lung tumour size reached $100 \mathrm{~mm}^{3}$, 14 days after implantation, the mice were grouped $(n=10)$ accord- 
ingly: (1) Control healthy, (2) Cancer-induced untreated control (saline vehicle only), (3) Cancer-induced and treated with $50 \mathrm{mg}$ Erlotinib/kg body weight (orally gavaged daily), (4 and 5) Cancerinduced and treated with 150 or $300 \mathrm{mg}$ extract $/ \mathrm{kg}$ body weight. After 21 days, they were sacrificed via intraperitoneal injection of ketamine $\mathrm{HCl}(100 \mathrm{mg} / \mathrm{kg})$ and xylazine $(10 \mathrm{mg} / \mathrm{kg})$ and the tumour volume was measured [5]. The lung and liver tissues were snap frozen in liquid nitrogen for gene expression analysis, while some were fixed in $10 \%$ formalin and embedded in paraffin for $\mathrm{H} \& \mathrm{E}$ and $\mathrm{IHC}$ examination [5]. The IHC primary antibody kits (ChemMate DAKO EnVision Detection Kit, Peroxidase/DAB, Rabbit/Mouse) were for (a) anti-EGFR (ab15669 from Abcam), (b) anti-MMP9 (Dako Corporation), and (c) anti-integrin (Novus) [31].

The tissue mRNA was isolated using Trizol (Invitrogen) and analysed quantitatively for VEGFA, AKT1, BCL2, MAP3K14, and MAPK1. The Custom RT2 Profiler PCR Array (CAPM11988), RT² SYBR Green qPCR Mastermix, RT² First Strand Kit, RNase-Free DNase Set (SuperArray Bioscience Corporation), and Data Analysis version 3.5 (SABiosciences) were used, with heat shock protein 90 alpha (cytosolic), class B member 1 (HSP90AB1; NM_008302), and glyceraldehyde-3-phosphate dehydrogenase (GAPDH; NM_008084) as housekeeping genes for mRNA analysis [5].

All data are the mean \pm standard deviation and were analysed by one-way analysis of variance (ANOVA) and Duncan's test for significant differences $(p<0.05)$ using IBM SPSS Statistics 21 software.

\section{Acknowledgments}

This study was supported by the Herbal Development Office, Ministry of Agriculture, Malaysia (Grant No. NH05135009).

\section{Conflicts of Interest}

The authors declare no conflict of interest.

\section{References}

[1] Ramalingam S, Sandler AB. Salvage therapy for advanced non-small cell lung cancer: Factors influencing treatment selection. Oncologist 2006; 11: 655-665

[2] Shepherd FA, Rodrigues Pereira J, Ciuleanu T, Tan EH, Hirsh V, Thongprasert S, Campos D, Maoleekoonpiroj S, Smylie M, Martins R, van Kooten M, Dediu M, Findlay B, Tu D, Johnston D, Bezjak A, Clark G, Santabárbara P, Seymour L. Erlotinib in previously treated non-smallcell lung cancer. N Engl J Med 2005; 353: 123-132

[3] Politi K, Fan P, Shen R, Zakowski M, Varmus H. Erlotinib resistance in mouse models of epidermal growth factor receptor-induced lung adenocarcinoma. Dis Model Mech 2010; 3: 111-119

[4] Deng S, West B, Jensen C. A quantitative comparison of phytochemical components in global noni fruits and their commercial products. Food Chem 2010; 122 : 267-270

[5] Lim SL, Goh YM, Noordin MM, Rahman HS, Othman HH, Abu Bakar NA, Mohamed S. Morinda citrifolia edible leaf extract enhanced immune response against lung cancer. Food Funct 2016; 7: 741-751

[6] West B, Tani H, Palu A, Tolson C, Jensen C. Safety tests and antinutrient analyses of noni (Morinda citrifolia L.) leaf. J Sci Food Agric 2007; 87: $2583-2588$
[7] Lagarto A, Bueno V, Merino N, Piloto ], Valdes O, Aparicio G, Bellma A, Couret $M$, Vega Y. Safety evaluation of Morinda citrifolia (noni) leaves extract: assessment of genotoxicity, oral short term and subchronic toxicity. J Intercult Ethnopharmacol 2013; 2: 15-22

[8] Nayak S, Mengi S. Immunostimulant activity of the extracts and bioactives of the fruits of Morinda citrifolia. Pharm Biol 2009; 47: 248-254

[9] West B, Deng S, Palu A. Antioxidant and toxicity tests of roasted noni (Morinda citrifolia) leaf infusion. Int J Food Sci Technol 2009; 44: 2142-2146

[10] Dussossoy E, Brat P, Bony E, Boudard F, Poucheret P, Mertz C, Giaimis ], Michel A. Characterization, anti-oxidative and anti-inflammatory effects of Costa Rican noni juice (Morinda citrifolia L.). J Ethnopharmacol 2011; 133: 108-115

[11] Leinonen T, Pirinen R, Böhm J, Johansson R, Ropponen K, Kosma VM. Expression of matrix metalloproteinases 7 and 9 in non-small cell lung cancer. Relation to clinicopathological factors, $\beta$-catenin and prognosis. Lung Cancer 2006; 51: 313-321

[12] Mahller YY, Vaikunth SS, Currier MA, Miller SJ, Ripberger MC, Hsu YH, Mehrian-Shai R, Collins MH, Crombleholme TM, Ratner N, Cripe TP. Oncolytic HSV and erlotinib inhibit tumor growth and angiogenesis in a novel malignant peripheral nerve sheath tumor xenograft model. Mol Ther 2007; 15: 279-286

[13] Cai X, Yang J, Zhou J, Lu W, Hu C, Gu Z, Huo J, Wang X, Cao P. Synthesis and biological evaluation of scopoletin derivatives. Bioorg Med Chem 2013; 21: 84-92

[14] Liu XL, Zhang L, Fu XL, Chen K, Qian BC. Effect of scopoletin on PC3 cell proliferation and apoptosis. Acta Pharmacol Sin 2001; 22: 929-933

[15] Kim EK, Kwon KB, Shin BC, Seo EA, Lee YR, Kim JS, Park JW, Park BH, Ryu DG. Scopoletin induces apoptosis in human promyeloleukemic cells, accompanied by activations of nuclear factor $\mathrm{KB}$ and caspase-3. Life Sci 2005; 77: 824-836

[16] Kim D, Mollah ML, Kim K. Induction of apoptosis of SW480 human colon cancer cells by (-)-epicatechin isolated from Bulnesia sarmienti. Anticancer Res 2012; 32: 5353-5361

[17] Manuele MG, Ferraro G, Arcos ML, López P, Cremaschi G, Anesini C. Comparative immunomodulatory effect of scopoletin on tumoral and normal lymphocytes. Life Sci 2006; 79: 2043-2048

[18] Saha A, Kuzuhara T, Echigo N, Suganuma M, Fujiki H. New role of (-)-epicatechin in enhancing the induction of growth inhibition and apoptosis in human lung cancer cells by curcumin. Cancer Prev Res 2010; 3: 953-962

[19] Ravindranath MH, Saravanan TS, Monteclaro CC, Presser N, Ye X, Selvan SR, Brosman S. Epicatechins purified from green tea (Camellia sinensis) differentially suppress growth of gender-dependent human cancer cell lines. Evid Based Complement Alternat Med 2006; 3: 237-247

[20] Hodkinson PS, Elliott T, Wong WS, Rintoul RC, Mackinnon AC, Haslett C, Sethi T. ECM overrides DNA damage-induced cell cycle arrest and apoptosis in small-cell lung cancer cells through $\beta 1$ integrin-dependent activation of PI3-kinase. Cell Death Differ 2006; 13: 1776-1788

[21] Kim S, Rabbani ZN, Dewhirst MW, Vujaskovic Z, Vollmer RT, Schreiber EG, Oosterwijk E, Kelley MJ. Expression of HIF-1 $\alpha$, CA IX, VEGF, and MMP-9 in surgically resected non-small cell lung cancer. Lung Cancer 2005; 49: 325-335

[22] Siefert SA, Sarkar R. Matrix metalloproteinases in vascular physiology and disease. Vascular 2012; 20: 210-216

[23] Montague R, Hart CA, George N], Ramani VA, Brown MD, Clarke NW. Differential inhibition of invasion and proliferation by bisphosphonates: anti-metastatic potential of Zoledronic acid in prostate cancer. Eur Urol 2004; 46: 389-402 
[24] Lin SS, Lai KC, Hsu SC, Yang JS, Kuo CL, Lin JP, Ma YS, Wu CC, Chung JG. Curcumin inhibits the migration and invasion of human A549 lung cancer cells through the inhibition of matrix metalloproteinase- 2 and -9 and vascular endothelial growth factor (VEGF). Cancer Lett 2009; 285: 127-133

[25] Karl E, Warner K, Zeitlin B, Kaneko T, Wurtzel L, Jin T, Chang J, Wang S, Wang CY, Strieter RM, Nunez G, Polverini PJ, Nör JE. Bcl-2 Acts in a proangiogenic signaling pathway through nuclear factor-kB and CXC chemokines. Cancer Res 2005; 65: 5063-5069

[26] Huang Q, Sheibani N. High glucose promotes retinal endothelial cell migration through activation of Src, PI3K/Akt1/eNOS, and ERKs. Am J Physiol Physiol 2008; 295: C1647-C1657

[27] Emerling BM, Weinberg F, Liu JL, Mak TW, Chandel NS. PTEN regulates p300-dependent hypoxia-inducible factor 1 transcriptional activity through Forkhead transcription factor 3a (FOXO3a). PNAS 2008; 105 : 2622-2627

[28] Lawson MH, Cummings NM, Rassl DM, Vowler SL, Wickens M, Howat WJ, Brenton JD, Murphy G, Rintoul RC. Bcl-2 and $\beta 1$-integrin predict survival in a tissue microarray of small cell lung cancer. $\mathrm{Br}$ J Cancer 2010; 103: 1710-1715
[29] Klein S, de Fougerolles AR, Blaikie P, Khan L, Pepe A, Green CD, Koteliansky V, Giancotti FG. $\alpha 5 \beta 1$ Integrin activates an NF-KBdependent program of gene expression important for angiogenesis and inflammation. Mol Cell Biol 2002; 22: 5912-5922

[30] Carbonell WS, DeLay M, Jahangiri A, Park CC, Aghi MK. $\beta 1$ integrin targeting potentiates antiangiogenic therapy and inhibits the growth of bevacizumab-resistant glioblastoma. Cancer Res 2013; 73: 3145-3154

[31] Lim SL, Mustapha NM, Goh YM, Bakar NA, Mohamed S. Metastasized lung cancer suppression by Morinda citrifolia (Noni) leaf compared to Erlotinib via anti-inflammatory, endogenous antioxidant responses and apoptotic gene activation. Mol Cell Biochem 2016; 416: 85-97

[32] Lu Z], Song QF, Jiang SS, Song Q, Wang W, Zhang GH, Kan B, Chen L], Yang JL, Luo F, Qian ZY, Wei YQ, Gou LT. Identification of ATP synthase beta subunit (ATPB) on the cell surface as a non-small cell lung cancer (NSCLC) associated antigen. BMC Cancer 2009; 9: 16 